\title{
Antimicrobial peptide nisin induces spherical distribution of macropinocytosis-like cytokeratin 5 and cytokeratin 17 following immediate derangement of the cell membrane
}

\author{
Norio Kitagawa ${ }^{1,2,3,4}$ \\ ${ }^{1}$ Oral Medicine Research Center, Fukuoka Gakuen, Fukuoka, ${ }^{2}$ Department of Dental Hygienist, Fukuoka College of Health Sciences, Fukuoka, \\ ${ }^{3}$ Department of Morphological Biology, Fukuoka Dental College, Fukuoka, ${ }^{4}$ Wellbeing Laboratory, Fukuoka, Japan
}

\begin{abstract}
The anti-aging effects of Lactococcus lactis are extensively investigated. Nisin is an antimicrobial peptide produced by L. lactis subsp. lactis. We previously reported that 24-hour nisin treatment disturbs the intermediate filament distribution in human keratinocytes. Additionally, we showed that the ring-like distribution of the intermediate filament proteins, cytokeratin (CK) 5 and CK17 is a marker of nisin action. However, two questions remained unanswered: 1) What do the CK5 and CK17 ring-like distributions indicate? 2) Is nisin ineffective under the experimental conditions wherein CK5 and CK17 do not exhibit a ring-like distribution? Super resolution microscopy revealed that nisin treatment altered CK5 and CK17 distribution, making them spherical rather than ring-like, along with actin incorporation. This spherical distribution was not induced by the suppression of endocytosis. The possibility of a macropinocytosis-like phenomenon was indicated, because the spherical distribution was $>1 \mu \mathrm{m}$ in diameter and the spherical distribution was suppressed by macropinocytosis inhibiting conditions, such as the inclusion of an actin polymerization inhibitor and cell migration. Even when the spherical distribution of CK5 and CK17 was not induced, nisin induced derangement of the cell membrane. Nisin treatment for 30 minutes deranged the regular arrangement of the lipid layer (flip-flop); the transmembrane structure of the CK5-desmosome or CK17-desmosome protein complex was disturbed. To the best of our knowledge, this is the first study to report that CK5 and CK17 in a spherical distribution could be involved in a macropinosome-like structure, under certain conditions of nisin action in keratinocytes.
\end{abstract}

Key words: Aging, Nisin, Pinocytosis, Keratin-5, Keratin-17

Received August 22, 2021; Revised October 16, 2021; Accepted October 19, 2021

\section{Introduction}

Lactococcus lactis has an anti-aging effect. It enables extension of lifespan and development of features associated

Corresponding author:

Norio Kitagawa (iD

Oral Medicine Research Center, Fukuoka Gakuen, Fukuoka 814-0193, Japan

E-mail:kitagawan@kyudai.jp with slowed aging, such as suppression of skin thinning, reduction of skin ulcers, suppression of muscle mass reduction, and maintenance of bone density, in mice and humans [14]. Various L. lactis subspecies produce several antimicrobial peptides [5-7]. Nisin is one such peptide produced by L. lactis subsp. Lactis; it is used as a food preservative. In this study, we evaluated nisin as a representative antimicrobial peptide from L. lactis. The very low threshold of bacterial cells compared to that of mammalian cells is a reason for the frequent use of nisin as an antimicrobial peptide $[8,9]$. 
Nisin induces pores in the bacterial cell membranes. The lipid composition of the cell membrane differs between bacterial and human cells. A study using liposomes showed that nisin disturbs the lipid composition of the bacterial model at a concentration lower than that required for a similar effect in a human cell model [10]. However, at nisin concentrations above the threshold, the effects on human cells is unknown, although it is used as a food preservative [8]; a detailed study has been initiated recently [8, 11]. At the beginning of digestion, the oral mucosal epithelia encounter nisin. Fibroblasts and other cells of the lamina propria are covered with oral mucosal epithelia. Therefore, we investigated the action of nisin on oral mucosal epithelial cells rather than on fibroblasts, although they are one of the most frequently used cells to study antimicrobial peptide action. Oral mucosal epithelia are majorly composed of keratinocytes [12]. Therefore, in this study, we used $\mathrm{HaCaT}$ [13] cells, a widely used immortal human keratinocyte cell line that exhibits a uniform epithelial architecture when transplanted into nude mice.

The characteristics of keratinocytes are profoundly influenced by the calcium concentration in the medium $[14,15]$. Therefore, to verify the effect of nisin on HaCaT cells, it is important to consider the influence of calcium concentration in the medium.

Nisin exerts its effects on $\mathrm{HaCaT}$ cells at a concentration used for food preservation. Nisin induces a ring-like distribution of cytokeratin (CK) 5 and CK17, which could be related to some vesicles, such as endosomes. Therefore, CK5 and CK17 could be used as markers to evaluate the action of nisin on keratinocytes [8].

Intermediate filaments are intermediate-diameter cytoskeletons present between the actin filaments and microtubules. There are various types of intermediate filament proteins; the type of protein in each keratinocyte is determined by the organ in which the keratinocytes exist and by the degree of differentiation. Intermediate filaments and desmosome proteins were used in this study.

$\mathrm{CK}$ is an intermediate filament protein. There are $54 \mathrm{sub}-$ types of human CK. Based on the isoelectric point, CK subtypes are divided into type I and II. Type I is acidic CK. Type II is basic or neutral CK. CK is a hetero-tetramer, composed of type I and type II CK in a 1:1 ratio [12].

CK5 and CK14 are the characteristic CK type II and I proteins in the basal layer of keratinocytes [16]. However, the type I CK of active keratinocytes, such as that in fetal skin and cultured cells, is CK17 [17, 18]. Keratin assemblies can exist even under the inhibition of actin polymerization. However, actin is necessary to transport the precursors of keratin intermediate filaments; therefore, the inhibition of actin polymerization affects the distribution of keratin intermediate filaments [19].

The desmosome is an intercellular junction between the epithelial cells. Desmosomes anchor intermediate filaments in the cytoplasm. The desmosome-intermediate filament complex enables a group of epithelial cells to resist external forces in a cooperative manner. The desmosome is composed of desmoglein (DSG), a transmembrane glycoprotein, belonging to the cadherin family. The DSG extracellular domains of adjacent cells interact with each other. The assembly of desmosomes requires calcium; this is similar to the calcium requirement of an adherens junction, which is composed of cadherin [12, 14, 20].

Endocytosis incorporates extracellular substances into the intracellular environment. It is influenced by calcium concentration and temperature [21-23], with an inhibition in keratinocytes cultured at $7^{\circ} \mathrm{C}[22]$.

Intermediate filaments participate in endocytosis. However, the contribution of intermediate filaments to endocytosis is not well known, compared to that of other well-known cytoskeletons, such as actin filaments and microtubules [24].

Vimentin is an intermediate filament protein that participates in endocytosis. It contributes to vesicular motility, and the control of vesicular location. Vimentin is not expressed in the normal keratinocytes; but is expressed in cancer keratinocytes and mesenchymal-derived cells, such as fibroblasts. To the best of our knowledge, there are no reports that CK5, CK14, or CK17 contribute to endocytosis or that intermediate filament proteins, including vimentin and $\mathrm{CK}$, are distributed as encompassing vesicles.

Macropinocytosis is a type of endocytosis $[25,26]$. The protrusions that participate in macropinocytosis are called lamellipodia, filopodia, or blebs. Lamellipodia and filopodia have an actin lining; but it is absent in blebs. The instability of the actin cortex results in bleb formation $[25,26]$. Therefore, macropinocytosis is dependent on actin expression [27].

Macropinosomes are larger than the endosomes of clathrin- and caveola-mediated endocytosis; the size is heterogeneous with diameters usually above $0.2 \mu \mathrm{m}$, and can sometimes be $>1 \mu \mathrm{m}[26,28]$. Macropinocytosis is common only in macrophages.

Macropinocytosis is conserved from amoebas to humans. 
In amoeba, it is negatively correlated with migration [29]. There is a negative correlation between pseudopodia formation and macropinocytosis. The same correlation could exist in human cells.

Some antimicrobial peptides affect the cell membrane. Magainin, a well-studied antimicrobial peptide, induces a flip-flop in mammalian cell membranes [30].

When a flip-flop occurs, the lipids in the inner layer move to the outer layer of the lipid bilayer. Therefore, phosphatidylserine, which is usually present in the inner layer, could be observed in the outer layer of the lipid bilayer.

Cell-penetrating peptides and antimicrobial peptides are similar in function [31]. Many cell-penetrating peptides [31] and antimicrobial peptides, including nisin [32] are cationic. Cell-penetrating peptides are incorporated via endocytosis and direct permeation [33-35]. Cell-penetrating peptides are incorporated through macropinocytosis and caveola- and clathrin-mediated endocytosis; the cell-penetrating peptides lead the macropinocytosis [36], resulting from interactions with proteoglycans in the cell membrane [37]. Accumulation of cell-penetrating peptides on the cell membrane proteoglycan leads to Racl activation, which in turn induces macropinocytosis [36]. The induction of endocytosis does not inhibit other endocytosis or direct permeation. Several mechanisms for cell-penetrating peptide incorporation can occur concurrently $[35,38]$.

Cell-penetrating peptides destroy cell membranes; however, cell-penetrating peptides also activate cell membrane repair through lysosomes, led by calcium influx into the cell [39]. Cell membrane repair makes it difficult to observe cell membrane damage using cell-penetrating peptides. Focusing on changes in intermediate filaments would enable better understanding of the cell membrane damage by cellpenetrating peptides.

In this study, we assessed previous studies on the CK5 and CK17 ring-like distributions. We also investigated whether nisin alters other cellular components under non-observed experimental conditions of CK5 and CK17 ring-like distribution.

To the best of our knowledge, this is the first report revealing a negative effect of nisin on epithelia, using morphological investigation at the nano-level. This knowledge is essential for the application of L. lactis, which is very promising for anti-aging.

\section{Materials and Methods}

\section{Materials}

Food-grade nisin was obtained from Sigma-Aldrich (St. Louis, MO, USA). Cytochalasin D was obtained from Cayman Chemical (Ann Arbor, MI, USA). Fetal bovine serum (FBS) was obtained from HyClone (Logan, UT, USA). Glass slides printed with highly water-repellent marks (cat. no. TF0215, TF1006) and cover slips were obtained from the Matsunami Glass Industry (Osaka, Japan). For super-resolution microscopy, cover slips with high tolerance $(0.170 \pm 0.005$ $\mathrm{mm}$, Matsunami Glass Industry) were used.

\section{Cell culture and drug treatment}

HaCaT cells [13] were cultured in Dulbecco's modified Eagle's medium (DMEM) containing $10 \% \mathrm{FBS}, 2 \mathrm{mM}$ glutamine, $100 \mu \mathrm{g} / \mathrm{ml}$ streptomycin, and $100 \mathrm{mg} / \mathrm{ml}$ penicillin. This culture medium contained approximately $2.2 \mathrm{mM}$ calcium.

Cells were seeded on seeding chamber slides on glass slides with water-repellent marks. The Applied Cell Extracellular Matrix (Applied Biological Materials Inc., Richmond, BC, Canada) was used for coating. For super-resolution microscopy investigation, cells were seeded at a low cell density $\left(4.0 \times 10^{4}\right.$ cells $\left./ \mathrm{cm}^{2}\right)$. This is because super-resolution microscopy is not suitable for capturing images with a high cell density.

Except for super-resolution microscopy observation, cells were seeded at a subconfluent density $\left(1.2 \times 10^{5} \mathrm{cells} / \mathrm{cm}^{2}\right)$ as in the previous experiment. After cell seeding, the cells were cultured for 2 days. The medium was changed the day after seeding and was cultured at $4^{\circ} \mathrm{C}$ or room temperature. The following day, the culture was subjected to nisin treatment at $4^{\circ} \mathrm{C}$ or room temperature.

After culturing for 2 days, cells were treated with a drug for 30 minutes or 24 hours. Either $93 \mu \mathrm{g} / \mathrm{ml}$ nisin or $93 \mu \mathrm{g} /$ $\mathrm{ml}$ nisin with $10 \mu \mathrm{M}$ cytochalasin $\mathrm{D}$ was added to the culture medium, as previously reported $[8,40,41]$. Cells grown in a medium containing $0.0015 \%$ acetic acid was used as the control.

\section{Ultralow calcium cell culture}

To remove calcium from the serum, $500 \mathrm{ml}$ of FBS was mixed with $20 \mathrm{~g}$ of Chelex 100 chelating resin (BioRad, Hercules, CA, USA) [42]. Calcium ultralow concentration medium and calcium-free DMEM (Nacalai Tesque, Kyoto, 
Japan) containing 10\% Chelex-treated FBS and $110 \mathrm{mg} / \mathrm{L}$ sodium pyruvate (Nacalai Tesque) were used. Calcium contamination can occur easily. For the calcium-free medium, a calcium ultralow concentration medium containing $0.1 \mathrm{mM}$ ethylene glycol-bis(2-aminoethylether)-N,N,N',N'-tetraacetic acid (EGTA) (Nacalai Tesque) was used. We gradually reduced the calcium concentration of the medium from 2.2 $\mathrm{mM}$ to a calcium ultralow concentration at each cell passage.

\section{Analysis of cell migration}

Silicon culture-insert 2-well (cat. no. 81176) was obtained from ibidi GmbH (Munchen, Germany) and used as previously reported [43]. We seeded cells in the insert; it was placed on a glass slide, similar to that used for other cultures in this study. One day after seeding, the medium was changed. During this change, the insert was removed to make a $500 \mu \mathrm{m}$-diameter cell-free gap for cell migration.

\section{Immunofluorescence microscopy}

Cells were fixed with $1 \%$ paraformaldehyde in phosphatebuffered saline (PBS) for 10 minutes, rinsed with PBS, and permeabilized using $0.2 \%$ Triton-X 100 in PBS for 15 minutes. The cells were washed with PBS and incubated in PBS containing $1 \%$ bovine serum albumin (BSA) for 15 minutes to block nonspecific binding. The cells were incubated with the primary antibodies at room temperature for 1 hour. After washing four times with PBS, the cells were incubated with appropriate secondary antibodies (1:400) in BSA-PBS for 30 minutes at room temperature in the dark. The cells were then washed four times with PBS and mounted in VECTASHIELD containing the nuclear counterstain 4',6-diamidino2-phenylindole (Vector Laboratories, Burlingame, CA, USA).

Rabbit polyclonal anti-CK5 (cat. no. SAB4501651; 1:100), anti-CK17 (cat. no. SAB4501662; 1:100), and anti-actin (cat. no. A2066; 1:100) antibodies were obtained from Sigma-Aldrich. Rabbit polyclonal anti-LAMP2 antibody (cat. no. GTX 103214; 1:100), and mouse monoclonal anti-DSG3 antibody (cat. no. GTX76040; 1:100) were purchased from GeneTex (Irvine, CA, USA). Mouse monoclonal anti-E-cadherin antibody (cat. no. 14472; 1:100) was purchased from Cell Signaling Technology Inc. (Beverly, MA, USA). Anti-mouse and anti-rabbit immunoglobulin (Ig) G antibodies conjugated with Alexa 488 (cat. nos. A11008 and A11034) and Alexa Fluor 568 (cat. nos. A11031 and A11036) (Molecular Probes, Eugene, OR, USA) were used as secondary antibodies. Alexa Fluor 568 conjugated phalloidin (cat. no. A12380) was pur- chased from Molecular Probes and used for F-actin observation using super-resolution microscopy.

Images were obtained using an LSM710 confocal laserscanning microscope (Zeiss, Oberkochen, Germany) or an $\mathrm{N}$-SIM super-resolution structured illumination system (Nikon, Tokyo, Japan). We used a 100× objective for each microscope, and the numerical aperture of the lens was 1.4, and 1.49 , respectively. Images and montages were generated using the in-built software from the microscope manufacturer and Adobe Photoshop elements (Adobe Systems Incorporated, San Jose, CA, USA). The same pseudo-color was used for each protein in all figures.

\section{Lamp2 distribution analysis}

The Lamp2 distribution area was recorded and evaluated using ImageJ software (ver. 1.52p; https://imagej.nih.gov/ij/). The Lamp2-positive areas in the DAPI-positive area were segregated, and the segmentation was conducted using the algorithm "Max Entropy". Lamp2-positive areas were counted using the function "analyze particle".

\section{Proximity analysis}

Proximity ligation assay (PLA) probes (Sigma-Aldrich) in antibody diluents were added to the slides, ligated, amplified, and washed according to the manufacturer's instructions. Negative controls were incubated without ligases or polymerase. The maximum intensity projection of the Zstack images using an LSM710 confocal laser-scanning microscope was used for the analysis. Proximity spots and nuclei of the images were extracted and counted using ImageJ software. After filtering the PLA image using the "median" method, image segmentation was conducted using the algorithm of "intermodes" or "minimum." Under the restriction of size and circularity, proximity spots were counted using the function "analyze particle." Non-specific red fluorescence, which increased in nisin-treated cells, was excluded by restricting for the size and circularity. It was difficult to discriminate between the proximity spots and cell debris for evaluating the actin-Ecad proximity spots and 24hour nisin-treated CK-DSG3 proximity spots. Therefore, under these conditions, we applied a machine learning system called the Trainable Weka Segmentation (https://imagej.net/ Trainable_Segmentation) before image segmentation using the algorithm of "intermodes" or "minimum". We trained the vector judgment ability of this plugin by providing examples of positive and negative areas, which were determined 
based on the size and circularity.

\section{Lipid flip-flop in $\mathrm{HaCaT}$ cells}

Fluorescein isothiocyanate-labeled annexin V was obtained from R\&D Systems Inc. (Minneapolis, MN, USA) and PromoKine (Heidelberg, Germany). Annexin V binds to phosphatidylserine; therefore, we used annexin $\mathrm{V}$ to detect the lipid flip-flop induced by 30 minutes nisin treatment.

The cells were incubated with annexin $V$ for 15 minutes in the dark according to a previous study and the manufacturer's instructions [30,44]. Cells were washed several times to remove unbound annexin $\mathrm{V}$. Images of paraformaldehydefixed cells and non-fixed cells were acquired and automatically tiled with a BZ-X700 fluorescence microscope (Keyence, Osaka, Japan) using a $20 \times$ or $40 \times$ objective with numerical apertures of 0.45 , and 0.95 , respectively. The ratio of annexin $\mathrm{V}$-positive cells was analyzed using the fixed-cell images. Images were analyzed using the hybrid cell count function of the BZ-X analyzer (Keyence).

\section{Cell viability assay}

Cell viability was determined based on the quantification of adenosine triphosphate levels using the Cell Titer-Glo 2.0 Assay kit (Promega, Madison, WI, USA) according to a previously described method and the manufacturer's instructions [8]. Cells were treated with $93 \mu \mathrm{g} / \mathrm{ml}$ nisin or vehicle for 30 minutes. To induce apoptosis, cells were treated with $1 \mu \mathrm{M}$ staurosporine (Cayman Chemical) for 24 hours. Luminescence was measured using a multi-label reader (PerkinElmer, Santa Clara, CA, USA). Viability was expressed as a percentage of the control.

\section{$3 D$ culture}

A total of $3.6 \times 10^{4}$ cells were seeded in 96-well U-shaped bottom plates specialized for 3D culture (cat. no. 174925, Nunclon Sphera; Thermo Fisher Scientific, NY, USA). This plate is designed for minimal cell attachment to the well plate surfaces; and therefore, it consequently, supports the formation of 3D cell clusters. Treatment with $93 \mu \mathrm{g} / \mathrm{ml}$ nisin or a dilution series of nisin or vehicle was performed for the indicated period in the Fig. 10. All the cells were cultured for 24 hours from the time of seeding. For phase-contrast microscopy, a BZ-X700 with a $4 \times$ (numerical aperture 0.13 ) objective was used.

\section{Statistical analysis}

Values are expressed as the mean \pm standard deviation (SD). Differences between groups were evaluated using the MannWhitney $U$ test. The $U$ test was performed using IBM SPSS Statistics 25 (IBM Corp., Armonk, NY, USA). Statistical significance was set at $P<0.05$.

\section{Results}

\section{The 24-hour nisin treatment induces spherical distribution of CK5 and CK17}

In 24-hour nisin-treated cells, CK5 and CK17 exhibited a spherical distribution similar to that of a fishbowl (Fig. $1 \mathrm{~A} ;$ no. 4,8$)$. This spherical distribution was very large. The diameter was greater than $1 \mu \mathrm{m}$. This spherical distribution appeared to encompass vesicles during endocytosis or exocytosis. In the X-Y plane, the cut surface of the spherical distribution had a circle-band-shaped distribution of CK5 and CK17 filaments (Fig. 1B). This circular band appears as a ring-like distribution, as observed in previous confocal microscopy studies.

In contrast, treatment with nisin for 30 minutes did not induce this spherical distribution, similar to that in the control at 30-minute or 24-hour (Fig. 1A; no. 1-3, 5-7). At the periphery of the cell membrane, interspaces between intermediate filaments were observed in all treatments, including the control (Fig. 1A). However, the interspace between intermediate filaments at the periphery of the cell membrane was apparently different from the spherical distribution in cells treated with nisin for 24 hours. These interspaces between intermediate filaments were small and ringed, not spherical (Fig. 1A).

Actin participates in spherical distribution in some high Z-axis positions (Fig. 1B; no. 4', 8'). Actin participation was easily observed in the X-Y plane (Fig. 1B; no. 4", 8"). In the spherical distribution region where actin participates, CK5 and CK17 distribution is weaker than that in the other regions of the spherical distribution (Fig. 1B; no. 4", 8"). The $\mathrm{X}-\mathrm{Z}$ plane indicated that actin participated in the spherical distribution at the periphery of the cell membranes (Fig. 1B; no. 4", 8"). Actin at the periphery of the cell membrane is the usual structure of the control cells. In the X-Z and $\mathrm{Y}-\mathrm{Z}$ planes, these actin distributions at the cell periphery were observable even in nisin-treated cells, similar to that in the control cells (Fig. 1B). The nisin-induced spherical distribution was located inside the actin layer at the periphery of the 

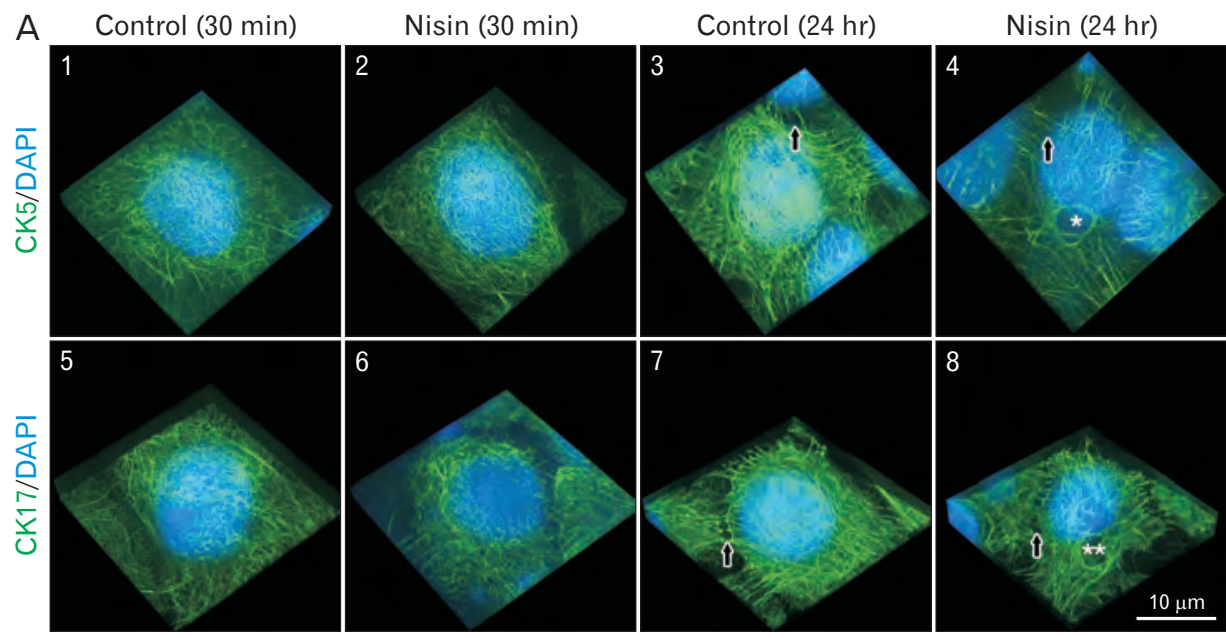

B

CK5/actin/DAPI

CK17/actin/DAPI

Nisin (24 hr)

Nisin (24 hr)
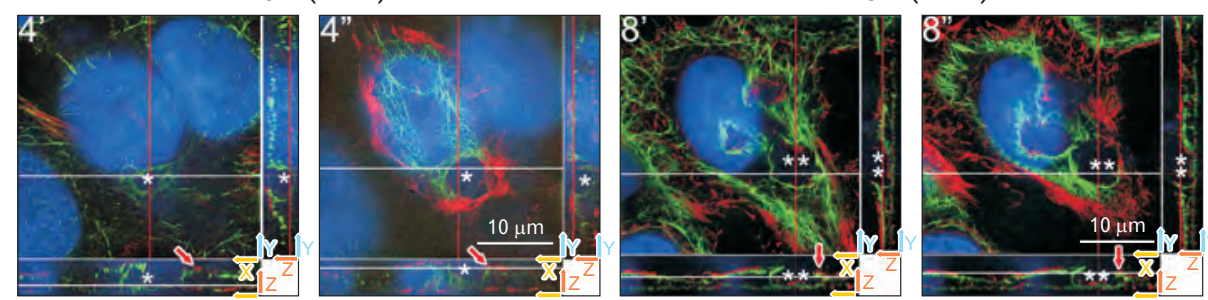

î Actin at periphery of cell membrane.

$\uparrow$ Interspaces between intermediate filaments at periphery of cell membrane.

Fig. 1. The 24-hour nisin treatment induces a spherical distribution composed of cytokeratin (CK) 5, CK17, and actin. (A) The 24-hour nisin-treated cells exhibit a spherical distribution similar to that of a fishbowl (asterisk or double asterisk at no. 4 or 8) and slightly sparse CK5 and CK17 intermediate filament distribution, except in the area of the spherical distribution. 3D images consist of stacked super resolution microscopy images (green) and fluorescence microscopy (blue) along the z-axis. (B) Cut surface of no. 4 and 8 in Fig. 1A. Difference between no. 4' and no. 4" or no. 8' and no. 8" are the height of the Z-axis direction in the X-Y plane, which is shown in the upper left window. Upper left window is the white line height section of the lower window. Upper left window can also be explained as the red line height section of the right window. Two arrows at the right lower corner of each window indicate the axis of each plane; (B) rotated approximately 45 degrees counterclockwise compared to (A). The meaning of each indicator is illustrated. Scale bars represent $10 \mu \mathrm{m} .{ }^{*}$ Same spherical distribution as shown in no. 4 of Fig. $1 \mathrm{~A}$ and no. 4', 4" of Fig. 1B. ${ }^{* *}$ Same spherical distribution as shown in no. 8 of Fig. 1A and no. 8', 8” of Fig. 1B.

cell membrane (Fig. 1B). Therefore, the spherical structure is an intracellular component.

\section{Nisin disturbs dense, uniform distribution of CK5 and CK17}

In the 24-hour control, many dense cells had intermediate filaments composed of CK5 and CK17 (Fig. 1A; no. 3, 7). These intermediate filaments are distributed as overgrown thickets. In many of the 24-hour nisin-treated cells, the thicket was apparently thinned out in the distributions compared to the overgrown thicket-like distribution in the control (Fig. 1A; no. 4, 8). Upon close examination, the 24hour nisin treatment indicated slightly sparse CK5 and CK17 intermediate filament distribution, except in the area of spherical distribution (Fig. 1A; no. 4, 8). There were no significant differences in the cells treated with nisin for 30 minutes, compared to that in the control cells (Fig. 1A; no. 1, $2,5,6)$.

\section{Nisin did not induce spherical distribution under $4^{\circ} \mathrm{C}$ culture}

$\mathrm{HaCaT}$ cells were treated with nisin at $4^{\circ} \mathrm{C}$ to determine whether the spherical distribution was dependent on endocytosis. As described in the introduction, endocytosis is usually inhibited at temperatures of $7^{\circ} \mathrm{C}$ or below. Nisin did not induce the spherical distribution of CK5 and CK17 at $4^{\circ} \mathrm{C}$ (Fig. 2). 


\section{The nisin effects against CK5 and CK17 require calcium in culture medium}

Abrupt changes in the calcium concentration in the culture medium drastically changes the keratinocyte characteristics. Therefore, we gradually decreased the calcium concentration in the culture medium at every passage. The

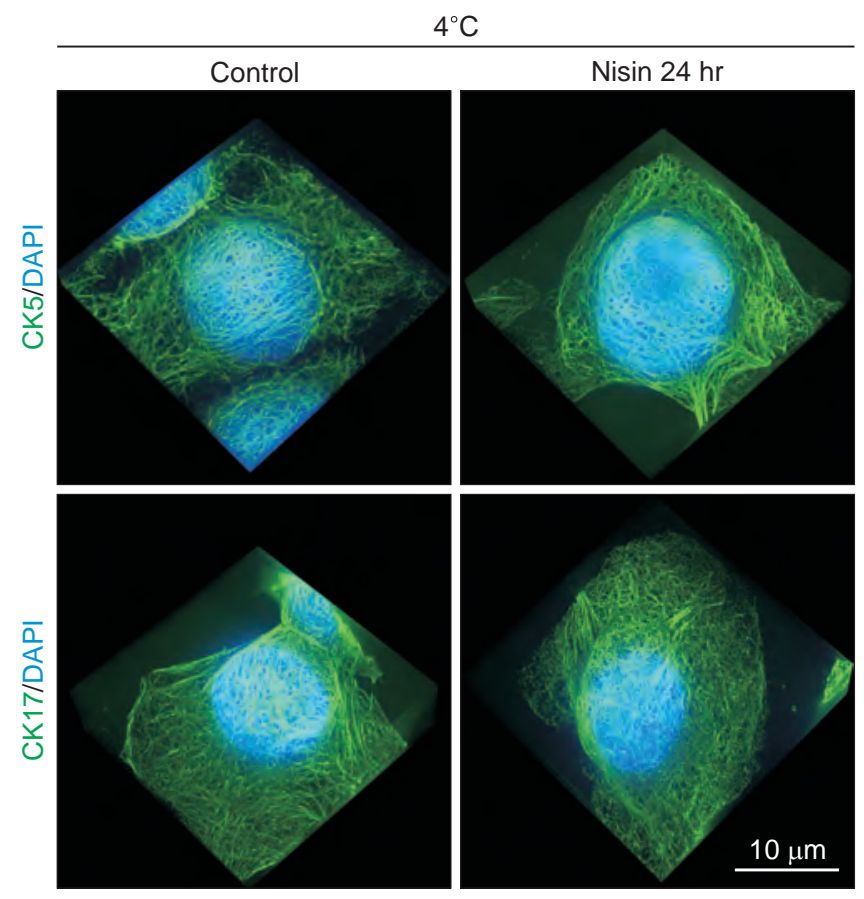

Fig. 2. Under $4^{\circ} \mathrm{C}$ culture, nisin did not induce a spherical distribution that is composed of cytokeratin (CK) 5 and CK17. Slightly sparse CK5 and CK17 intermediate filament distribution were also not induced. 3D images consisting of stacked super resolution microscopy images (green) and fluorescence microscopy (blue) along the z-axis. Scale bar represent $10 \mu \mathrm{m}$. distribution of CK5 and CK17 was similar to that in culture with the usual calcium concentration and in that with low calcium acclimated cells under control conditions (Figs. 1, 3).

However, there was an increase in the intercellular gaps (data not shown). This is common in low calcium concentration medium; it could be attributed to the loss of cell junctions that require calcium. The CK5 and CK17 intermediate filaments were thicker than those in cells cultured in normal medium (Figs. 1, 3).

HaCaT cells reacted differently to nisin in the calcium ultralow concentration medium compared to that in the usual culture. Nisin treatment did not induce a spherical distribution of CK5 and CK17 in the ultralow calcium concentration medium (Fig. 3) or in calcium-free medium supplemented with EGTA (0.1 mM) (data not shown). There were no significant differences in the density of CK5 and CK17 intermediate filaments in ultralow calcium medium (Fig. 3). There was no significant difference in the distribution of CK5 and CK17 intermediate filaments between the control and nisin treated cells, which were also not significantly different from those of the control at 30 minutes and 24 hours.

\section{Nisin-induced spherical distribution was not observed in culture medium with cytochalasin-D}

Cytochalasin, an actin polymerization inhibitor, suppresses macropinocytosis. When cytochalasin-D was added to the culture medium, actin filaments were not observed (data not shown); nisin did not induce the spherical distribution of CK5 and CK17 (Fig. 4).

The interspaces of CK5 and CK17 were observed under all conditions (Fig. 4); however, these interspaces were apparent-

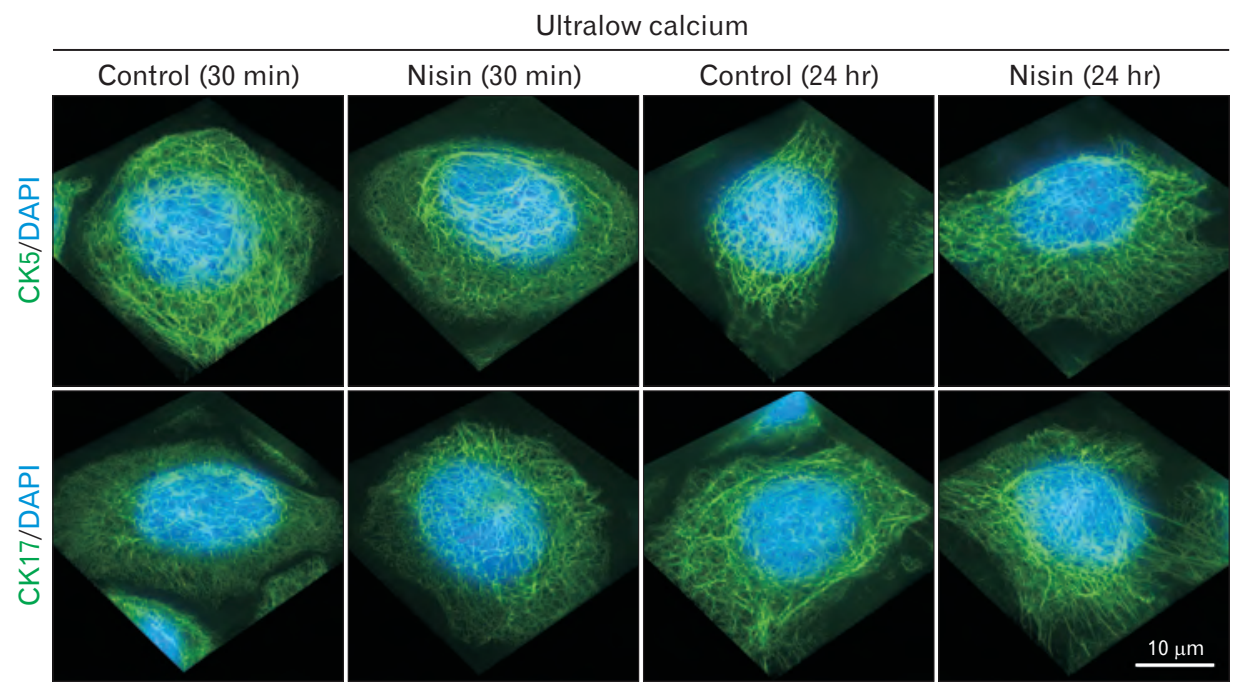

Fig. 3. In ultralow calcium concentration medium, nisin did not cause a spherical distribution that is composed of cytokeratin (CK) 5 and CK17. Slightly sparse CK5 and CK17 intermediate filament distribution were also not induced. 3D images consist of stacked super resolution microscopy images (green) and fluorescence microscopy (blue) along the z-axis. Scale bar represent $10 \mu \mathrm{m}$. 

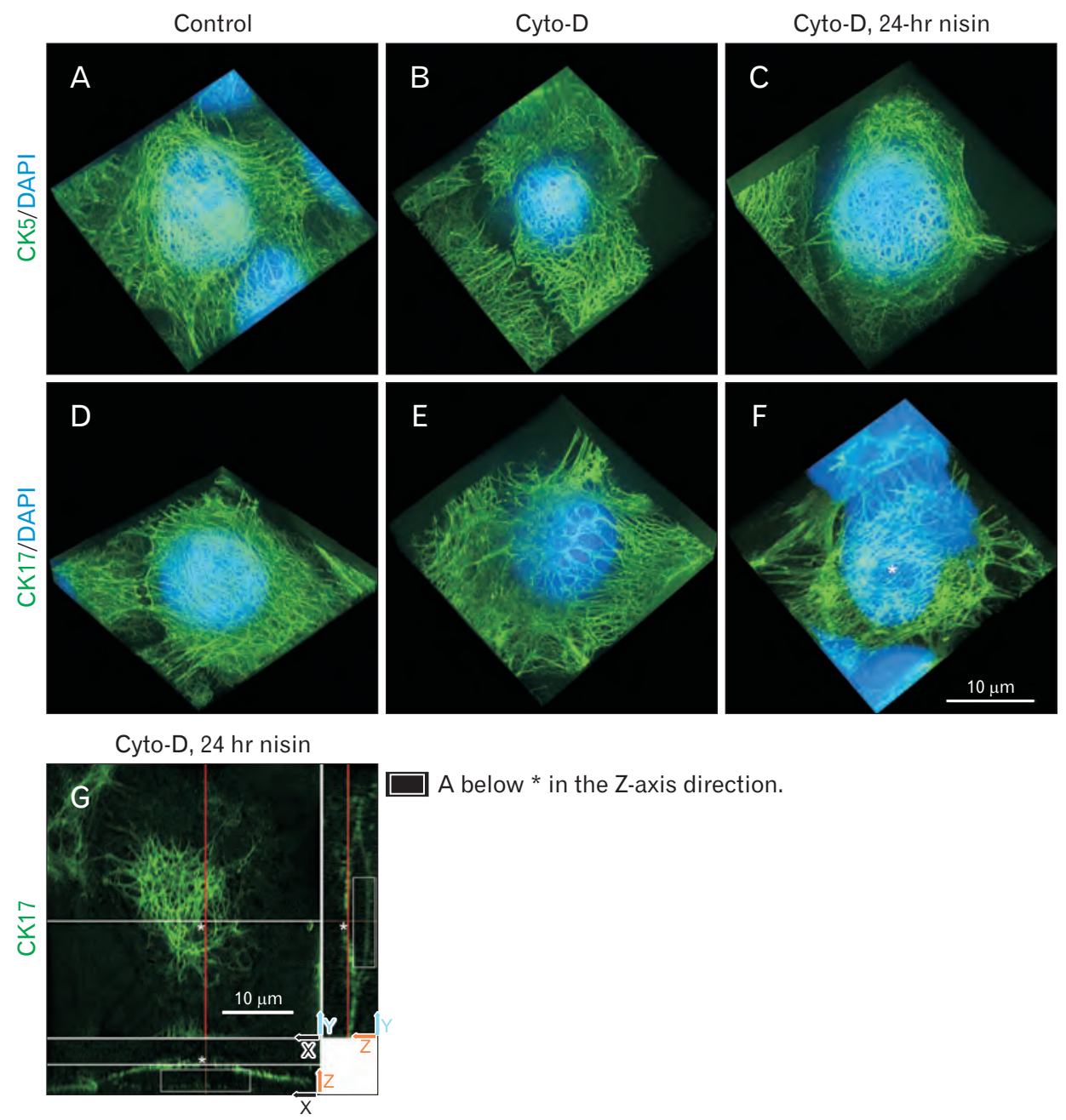

Fig. 4. Actin polymerization inhibitor cytochalasin (cyto)-D suppresses nisin-induced spherical distribution composed of cytokeratin (CK) 5 and CK17. Interspacing between CK17 intermediate filaments (asterisk) are presented as a 2D structure and it is different from the 3D spherical distribution in Fig. 1. This interspacing could only be observed in the X-Y plane. In the X-Z plane or Y-Z plane, the interspacing observed in the X-Y plane did not exist. (A-F) 3D images consist of stacked super resolution microscopy images (green) and fluorescence microscopy (blue) along the z-axis. Control conditions shown in panels (A) and (D) are with the same data as that in Fig 1A no. 3 and 7. (G) Cut surface of (F). Upper left window is the white line height section of the lower window. Upper left window can also be explained as the red line height section of the right window. Two arrows at right lower corner of each window indicate the axis of each plane. Panel (G) have been rotated approximately 45 degrees counterclockwise compared to $(\mathrm{F})$. The meaning of each indicator is illustrated. Scale bars represent $10 \mu \mathrm{m}$. ${ }^{*}$ Interspaces between CK17 intermediate filaments.

ly different from that in the nisin-induced spherical distribution of CK5 and CK17 (Fig. 1); they were 2D structures (Fig. $4 \mathrm{G})$. Interspacing could only be observed in the X-Y plane. In the X-Z plane or Y-Z plane, interspacing similar to that in the $\mathrm{X}-\mathrm{Y}$ plane did not exist (Fig. 4G).

\section{E-cadherin exhibits a wavy distribution in nisin- treated cells}

E-cadherin was distributed almost homogeneously at the control cell boundary (Fig. 5). It was distributed in a gently curved line with almost the same thickness and density.

Treatment with nisin for 24 hours disrupted this gentle curving line distribution and induced a ruffled distribution (Fig. 5). The ruffled distributions were composed of the Ecadherin with nonequivalent thickness and nonequivalent density near the cell boundary. In nisin-treated cells, some E-cadherin line-like distributions appeared at right angles to other line-like E-cadherin distributions. 


\section{The 24-hour nisin-treatment increased cytoplasmic expression of Lamp II}

In the 24-hour nisin-treated cells, numerous lysosomemarkers, such as Lamp II, were distributed in the cytoplasm, compared to that in the control cells (Fig. 6). Additionally, at 24-hour of nisin treatment, the distribution of Lamp II in the nucleus or in the periphery of the nucleus was weaker than that in the cytoplasm. In contrast, in control cells or 30-minute nisin-treated cells, Lamp II was distributed in the nucleus or in the periphery of the nucleus (Fig. 6). In the ultralow calcium medium, the cytoplasmic distribution of Lamp II was not increased by nisin (Supplementary Fig. 1).

\section{Nisin decreased proximity of DSG3 with CK5 or CK17}

A decrease in the proximity of DSG3 with CK5 or CK17 and E-cadherin with actin after 30 minutes or 24 hours of nisin treatment was observed in the PLA assay (Fig. 7A). The decrease in the number of proximity spots was statistically significant (Fig. 7B), in both the 30-minute and 24-hour nisin treatments.

\section{The 30-minute nisin treatment induced flip-flop of phosphatidylserine}

Treatment with nisin for 30 minutes significantly increased the number of Annexin-V-positive cells, indicating a flip-flop of phosphatidylserine (Fig. 8). This flip-flop induction was 9-fold higher in nisin-treated cells than that in control cells (Fig. 8B). To confirm that this flip-flop is not a part of the apoptosis reaction, we checked cell viability. Cell viability was not affected by the 30-minute nisin treatment (Fig. 8C).

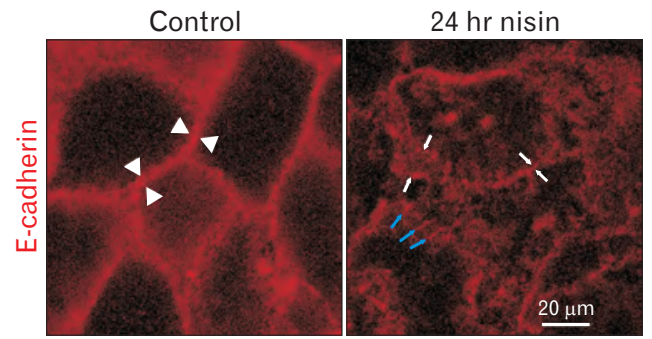

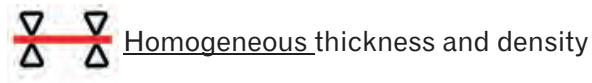

If Nonequivalent thickness and density

Distribution appears in right angle directions to other parts of the distribution.

Fig. 5. Disruption of regular E-cadherin distribution in cell boundary following 24-hour nisin treatment. Thickness and density of E-cadherin distribution changed from homogenous to nonequivalent following nisin treatment. Some E-cadherin line-like distributions appeared at right angles to the other line-like E-cadherin distributions in nisin-treated cells. Confocal microscopy images. Difference in thickness, density, and direction of E-cadherin line-like distribution illustrated by indicator. The meaning of each indicator is illustrated. Scale bar represents $20 \mu \mathrm{m}$.
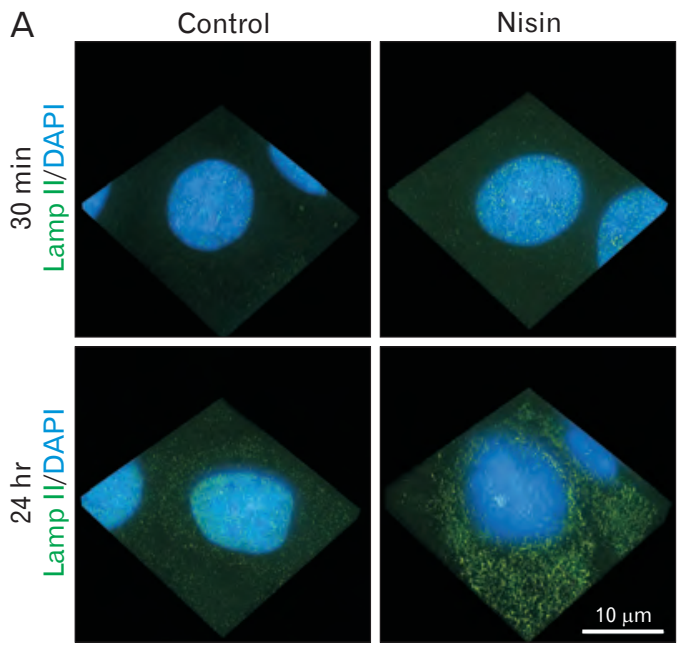

B

Nucleus (dapi positive region) Cytoplasm

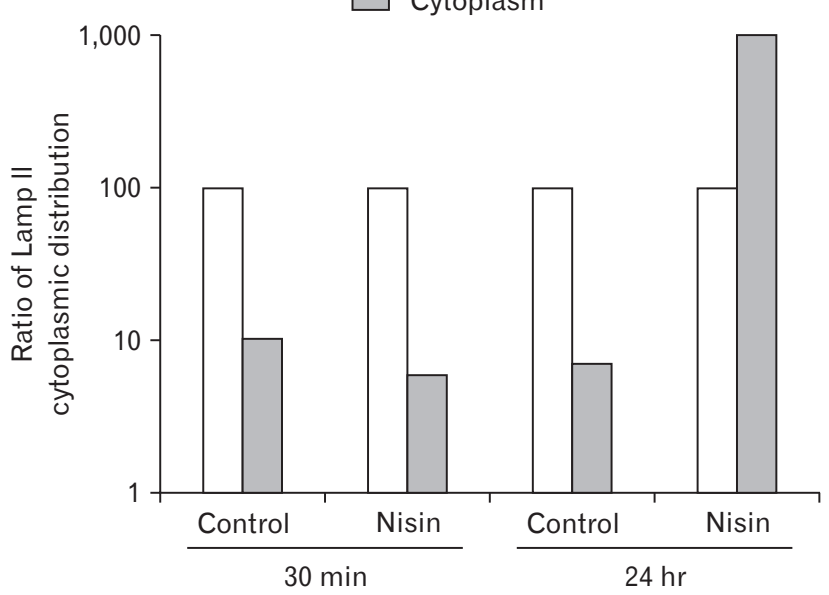

Fig. 6. The 24-hour nisin treatment increases cytoplasmic distribution of the lysosome marker, Lamp II. Except in the 24-hour nisin treatment, the distribution of Lamp II in the cytoplasm was lesser than that in the nucleus or periphery of the nucleus. (A) 3D images consist of stacked super resolution microscopy images (green) and fluorescence microscopy (blue) along the z-axis. (B) Bar graph comparing Lamp II distribution in the cytoplasm and nucleus. Scale bar represent $10 \mu \mathrm{m}$. 
A
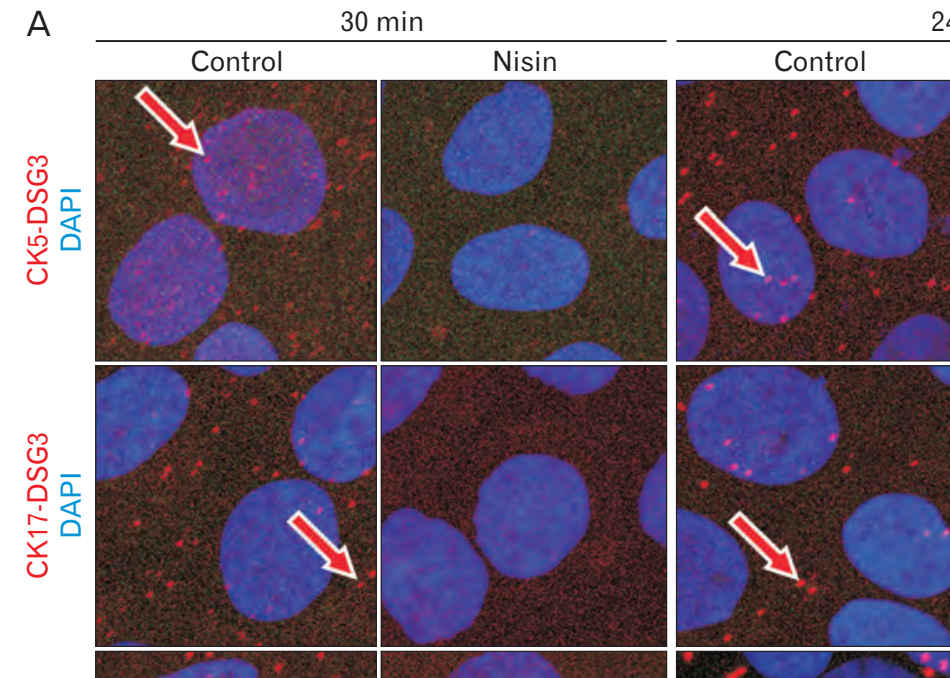

$24 \mathrm{hr}$

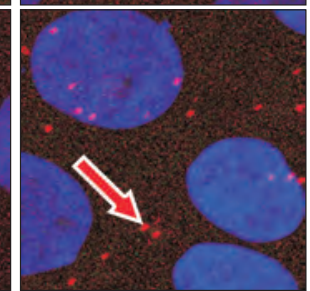

Nisin
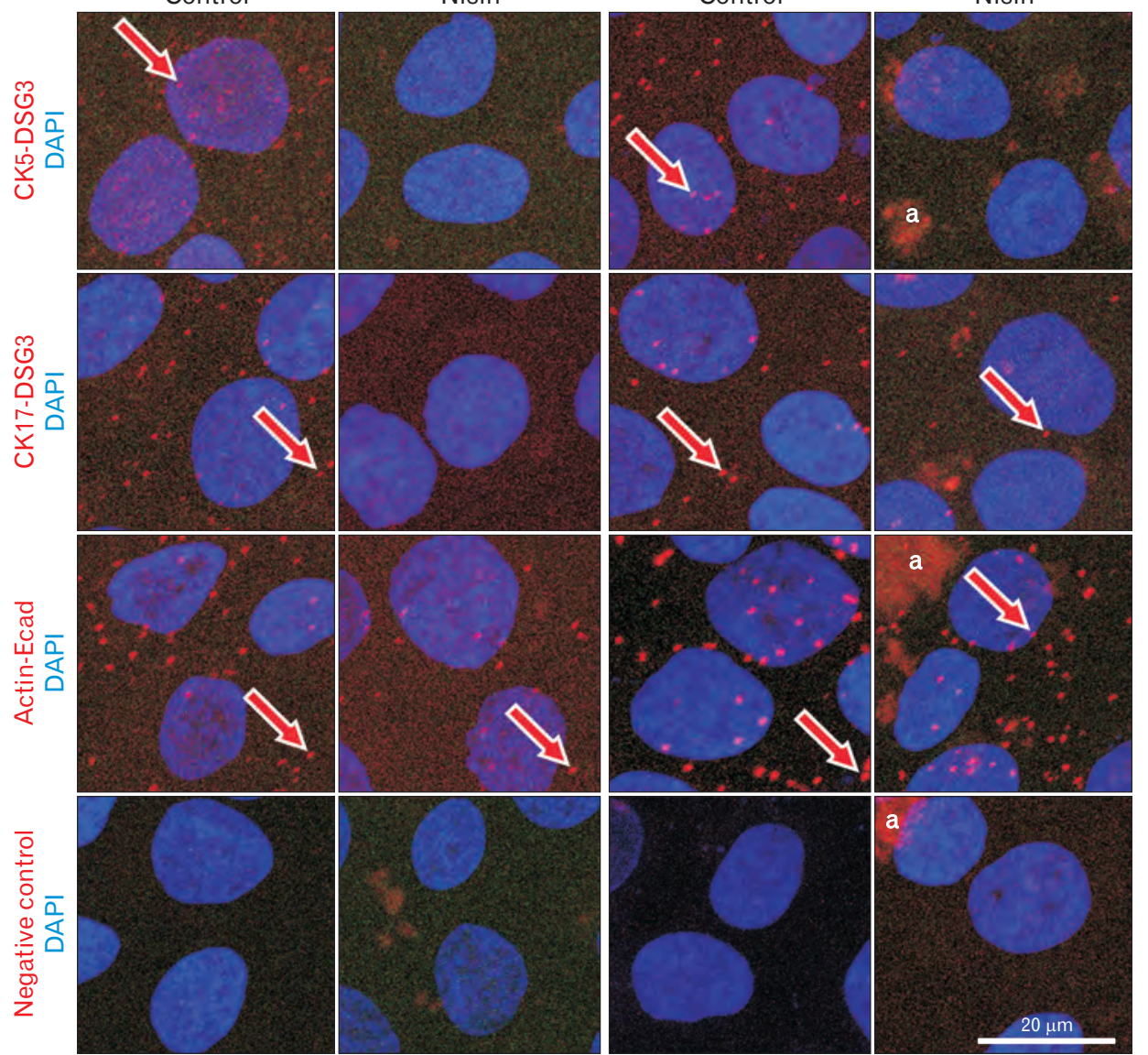

B

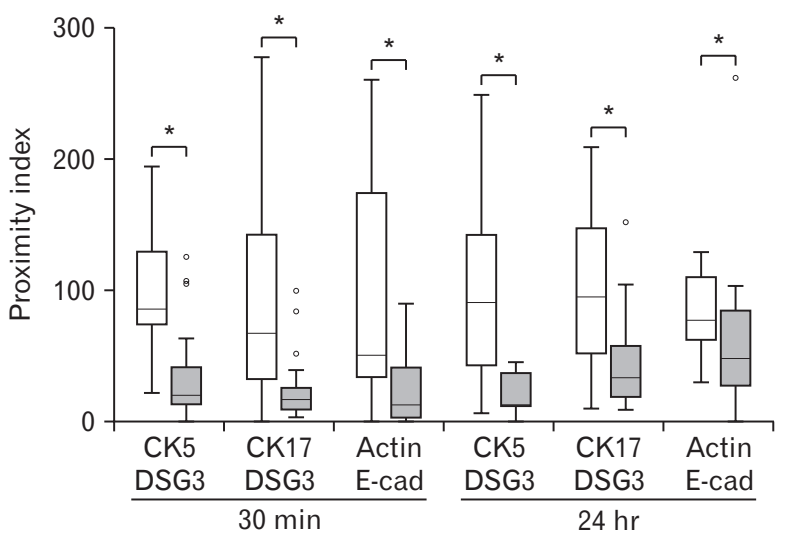

\section{Nisin does not induce a spherical distribution in migrating cells}

In migrating cells, the spherical distribution of CK5 and CK17 was not distinctly induced by nisin (Fig. 9). Other types of distribution changes in CK5 and CK17, excluding spherical distribution, were also not induced by nisin in migrating cells (Fig. 9). Differences, such as "thinned out thicket-like distribution" vs. "overgrown thicket-like distri-

bution" in cells surrounded by other cells, were not observed in migrating cells.

\section{Nisin disturbed the formation of $3 D$-cell clusters}

Keratinocytes are stratified in vivo. Therefore, we investigated the effect of nisin on stratified cells by observing globose cell cluster formation. Nisin treatment performed simultaneously with cell seeding (0-24 hours) or 3 hours af- 
A

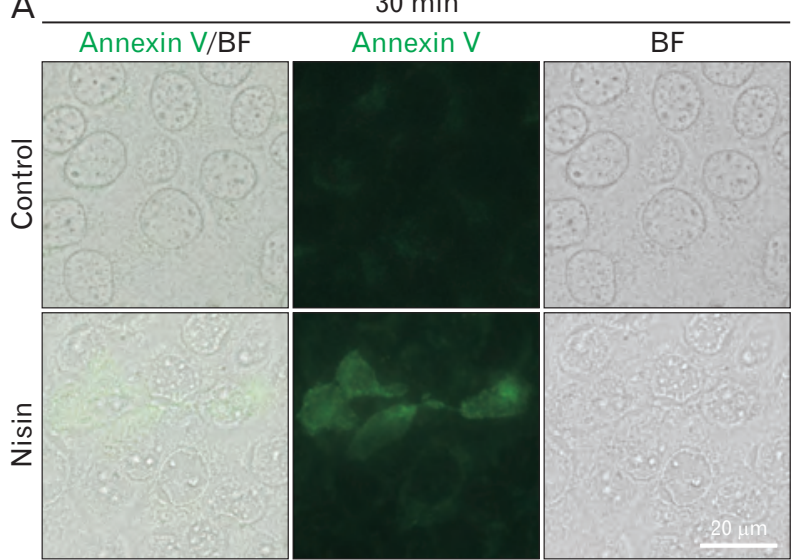

B

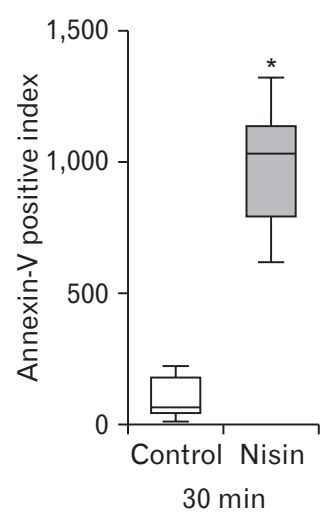

C

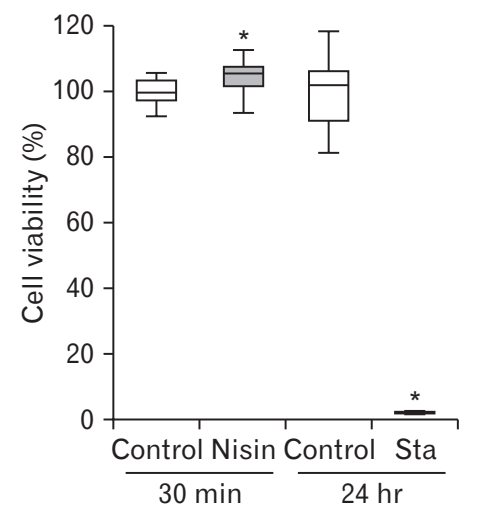

Fig. 8. Increase in flip-flops following 30-minute nisin treatment. (A) Green fluorescence of annexin V induced by nisin indicates flip-flop. Fluorescence and bright field (BF) microscopy images in unfixed cells. Scale bar $=20 \mu \mathrm{m}$. (B) Quantitative analysis of flip-flops. When index of the image is 100, it means that the ratio of the annexin $\mathrm{V}$ positive cell is the same as the average ratio in the control images. (C) Viability after 30-minute nisin treatment or 24-hour after treatment with the apoptosis inducer, staurosporine. The line within the box plot represents the median value. Values are expressed as the mean $\pm \mathrm{SD}(\mathrm{n}>15) .{ }^{*} \mathrm{P}<0.05$ versus control.

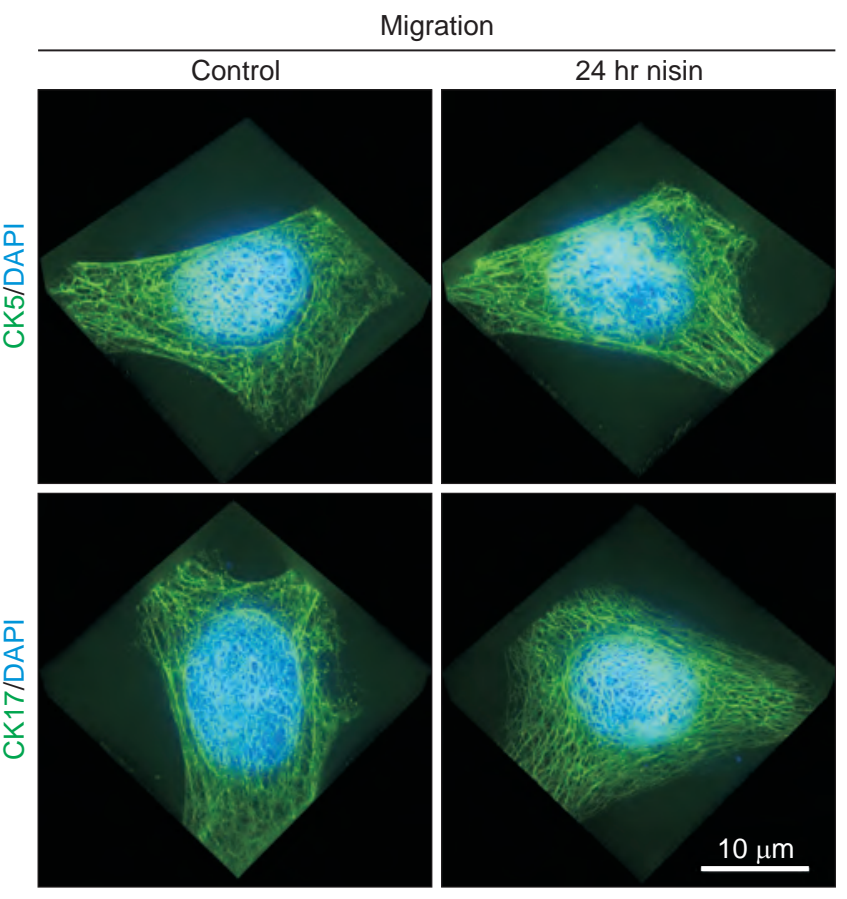

Fig. 9. In migrating cells, nisin does not induce spherical distribution of cytokeratin (CK) 5 and CK17. This reaction is different from that in cells surrounded by other cells in Fig. 1. Nisin treatment did not cause a slightly sparse CK5 and CK17 intermediate filament distribution. 3D images consist of stacked super resolution microscopy images (green) and fluorescence microscopy (blue) along the z-axis. Scale bar represent $10 \mu \mathrm{m}$.

ter cell seeding (3-24 hours) disturbed the globose-type cell cluster formation. In this case, cell clusters exhibited a sea urchin-shape and there was an increase in cell debris (Fig.

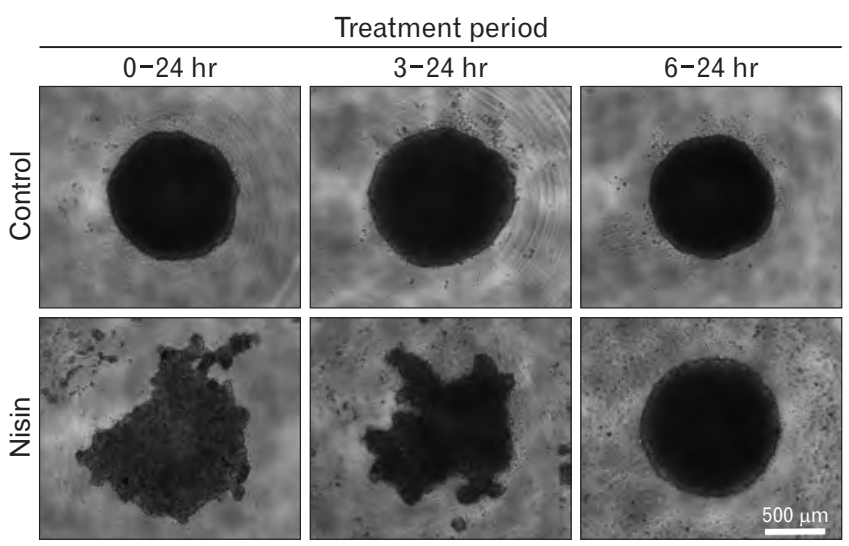

Fig. 10. Nisin blocked globose shape type 3D cell cluster formation. At 0 to 24 hours or 3 to 24 hours nisin treated cell clusters showed a sea urchin-shape, compared to that in the 6 to 24 hours treated cell cluster and control. HaCaT cells in minimal cell attachment plates were treated with nisin or the vehicle for indicated periods from seeding. Images of phase-contrast microscopy. Scale bar represent 500 $\mu \mathrm{m}$.

10); cell cluster formation was inhibited (data not shown).

This effect was dependent on nisin concentration. In the dilution series of nisin, the high nisin concentration disturbed the globose shape more than the low nisin concentration (data not shown).

However, at 6 hours after cell seeding, the globose-type cell cluster shape was not disturbed by nisin treatment (6-24 hours) (Fig. 10). Additionally, the 3D cluster diameter of nisin-treated $\mathrm{HaCaT}$ cells in the 6-24 hours group did not decrease compared to that in the control. 
In the calcium ultralow concentration medium, which is the condition in which the adhesion junction has difficulty forming, a globose-type cell cluster was not formed regardless of whether nisin treatment was performed (data not shown). Therefore, the action of nisin on stratified cells in ultralow calcium medium was difficult to determine.

\section{Discussion}

Super resolution microscopy revealed that the nisininduced ring-like distribution of CK5 and CK17 in a previous study had a spherical distribution, resembling a vesicleshaped structure. This distribution is composed of CK5, CK17, and actin. Under the conditions that suppress endocytosis or macropinocytosis, such as low temperature, ultralow calcium concentration, actin polymerization inhibitor, and migrating cell cultures, CK5, CK17, and actin did not induce this spherical distribution. Furthermore, as expected from a previous antimicrobial peptide study, cell membrane alterations were observed. Nisin increased Lamp II cytoplasmic distribution and disturbed the E-cadherin gentle curving line distribution. In contrast to the 24-hour treatment, the 30-minute nisin treatment did not induce a spherical distribution of CK5 and CK17. However, nisin induced other responses. Treatment with nisin for 30 minutes decreased the proximity of CK5 and CK17 to DSG3. The flip-flop of the cell membrane was also induced by 30 minutes of nisin treatment.

Spherical distribution was not observed in four endocytosis-suppressing conditions or macropinocytosis-suppressing conditions (Figs. 2-4, 9) [21-23, 27, 29]; therefore, we propose the possibility that nisin induces endocytosis. Additionally, the results of this study indicate the possibility that this large endosome is an endosome-like macropinosome.

Actin appears to be essential for this macropinocytosislike reaction, similar to that in macropinocytosis. Spherical distribution was not induced by nisin in cultures treated with an inhibitor of actin polymerization. Actin filaments are essential for the transport of CK precursors, including CK5 and CK17 [19]. In addition to the absence of actin filaments, the lack of CK precursor movement may also contribute to the suppression of the spherical distribution of CK5 and CK17.

To reinforce our hypothesis of nisin-induced endosomes, such as in macropinocytosis, vesicle membrane staining and investigation of regulatory factor activation will be needed in future studies. Rho GTPases, such as Rac1 and Cdc42 that are regulators of macropinocytosis, are ideal candidates for such investigation [25].

It is not clear, why CK5 and CK17 are distributed in the spherical distribution, if it is a macropinosome. The involvement of CK5 and CK17 in macropinocytosis has not been previously reported. This could possibly be explained based on the involvement of intermediate filament proteins in macropinocytosis. Vimentin participates in endocytosis [24]. Specifically, vimentin is involved in integrin trafficking and late endocytic trafficking. However, vimentin is a mesenchymal protein; while, $\mathrm{HaCaT}$ cells are epithelial cells. In $\mathrm{HaCaT}$ cells, vimentin was not observed under our experimental conditions (data not shown). In epithelial cells, CK may participate in macropinocytosis instead of vimentin. In general, CK17 distribution has many unsolved questions compared to CK17 protein expression [45]. Therefore, together with the nisin study, CK17 distribution requires further research.

We speculated that the purpose of this nisin-induced macropinocytosis-like reaction was a cell membrane shape adjustment. In neurons, massive internalization of the cell membrane by macropinocytosis occurs. This internalization of the cell membrane is related to the collapse of the growth cone [46]. In neurons, macropinocytosis is related to the adjustment of cell membrane shape. Therefore, in HaCaT cells damaged by nisin, macropinocytosis could be related to cell shape adjustment.

In addition to the macropinocytosis-like reaction, nisin induced a change that could contribute to cell membrane repair. Nisin changed the distribution of Lamp II from the nucleus or the periphery of the nucleus to the cytoplasm (Fig. 6). Vesicles, such as lysosomes, contribute to cell membrane repair [39]. Lysosome distribution is controlled by the mesenchymal intermediate filament protein vimentin [24, 47]; and therefore, the epithelial intermediate filament proteins CK5 and CK17 could also be related to the Lamp II distribution. Additionally, the macropinocytosis-like reaction and the changes in Lamp II distribution occur under similar induction conditions. Both vesicle-related reactions require calcium (Fig. 3, Supplementary Fig. 1) [39] and a 24-hour treatment time (Figs. 1, 6). Therefore, we hypothesized that macropinosome-like reactions and lysosomes could jointly counteract the cell membrane damage caused by nisin.

However, Lamp II was distributed throughout the cytoplasm, but it did not show a spherical distribution. Therefore, Lamp II distribution and macropinosome-like structure ap- 
pear to have different effects.

Disturbances in the regular intercellular E-cadherin distribution indicate cell membrane changes (Fig. 5), such as macropinocytosis-like endocytosis, small vesicle distribution, or derangement of the lipid bilayer regular arrangement. In addition to these three changes, other cell membrane changes could have occurred simultaneously. For example, considering its shape, E-cadherin distribution occurs at right angle to the other parts of E-cadherin distribution (Fig. 5), and could indicate a ruffling cell membrane in macropinocytosis $[25,26]$. During macropinocytosis, E-cadherin could be internalized into the cytoplasm from the cell membrane following ruffling [48]. Additionally, considering its shape, the cell periphery in the E-cadherin distribution exhibits non-equivalent thickness and the density was speculated to indicate the presence of small vesicles or derangement of the lipid bilayer regular arrangement. This includes E-cadherin recycling [49] or the diffusion of intracellular E-cadherin from the cell membrane to the cytoplasm.

Notably, in this study, the nisin effects occurred at a much shorter time and at a much lower nisin concentration than that in previous studies (24-hour and $47 \mu \mathrm{g} / \mathrm{ml}$, respectively) on thresholds of "ring like distribution," [8]. Disarrangement of the cell membrane began immediately after nisin treatment (Figs. 7, 8). The flip-flop of phosphatidylserine was observed after 30 minutes of nisin treatment (Fig. 8). Cell membrane disarrangements, such as flip-flops, disturbed the structure around the cell membrane. A decrease in the CK5DSG3 and CK17-DSG3 complexes, which are structures around the cell membrane, was induced after 30 minutes of nisin treatment (Fig. 7). Therefore, we concluded that even if there is no spherical distribution, nisin exerts effects on HaCaT cells.

Nisin induced the flip-flop of phosphatidylserine (Fig. 8). Annexin V, which was used to investigate the flip-flop in this study, was also used as an apoptosis marker. The flipflop induced by apoptosis takes several hours [30, 50]. In this study, the flip-flop was induced by 30 minutes of nisin treatment; and therefore, the possibility of apoptosis was ruled out. In addition, there was no drastic decrease in the viability of cells treated with nisin for 30 minutes, compared to that in apoptosis inducer-treated cells (Fig. 8C). In a previous study, the TUNEL assay revealed that nisin did not induce apoptosis [8].

The following effects of nisin on $\mathrm{HaCaT}$ cells indicate possible negative reactions in humans: a decrease in the
CK5-DSG3 and CK17-DSG3 complexes, inhibition of cellcluster formation, and an increase in flip-flops (Figs. 7, 8, 10).

Nisin exhibits a positive reaction to the epithelia and it promotes wound healing [11]. However, the underlying mechanism is not well understood. There are two possible reasons: nisin promotes cell migration [11]; this nisininduced promotion of cell migration contributes to wound healing. Nisin switches the mainstream of endocytosis into another type. Cell penetrating peptides, which are very similar to nisin, induce this switchover. This switch leads to burn wound healing in fibroblasts [51]. For example, the switchover from clathrin-dependent endocytosis to macropinocytosis changes the remaining compartment of the engulfed growth factor. This change in the staying compartment may increase the effect of growth factors in nisin-treated $\mathrm{HaCaT}$ cells.

To apply our 2D culture cell study to human oral epithelia, we used the cell cluster model shown in Fig. 10. The non-keratinizing property, which is the same as that in most human oral epithelia, is a merit of the cell cluster model, compared to rodent models, in which oral epithelia are keratinized. We confirmed that nisin action on $\mathrm{HaCaT}$ cells occurred not only in the $2 \mathrm{D}$ cell culture, but also in the $3 \mathrm{D}$ cell cluster (Fig. 10). A decrease in the CK5-DSG3 and CK17DSG3 complexes and an increase in flip-flops could be related to the suppression of cell cluster formation. This model has recently clarified that the maturity of keratinocytes is an important factor for nisin action in 3D experiments, because nisin does not destroy or alter the shape of the 6 hour-passed 3D-cell clusters (Fig. 10).

In conclusion, to the best of our knowledge, this is the first study at nano-level to report that actin, CK5, and CK17 could contribute in macropinocytosis-like reactions. Nisin damaged cells, at a nisin concentration and duration in which this macropinocytosis-like reaction was not induced. For defense, $\mathrm{HaCaT}$ cells might have reacted against nisin treatment, as described in this report. Nisin is difficult to label using fluorescence; therefore, clarifying its effect on mammalian cells is difficult. The results from this study provide insights into the possible utilization of nisin. In addition, it could contribute to the utilization of L. lactis, as an anti-aging agent.

\section{ORCID}

Norio Kitagawa: https://orcid.org/0000-0001-5565-4210 


\section{Author Contributions}

Conceptualization: NK. Data acquisition: NK. Data analysis or interpretation: NK. Drafting of the manuscript: NK. Critical revision of the manuscript: NK. Approval of the final version of the manuscript: all authors.

\section{Conflicts of Interest}

No potential conflict of interest relevant to this article was reported.

\section{Acknowledgements}

This study was supported by JSPS KAKENHI Grants (numbers 15K21564 and 17K18302), the Private University Research Branding Project to Fukuoka College of Health Science from the Ministry of Education, and a grant from the Oral Medicine Research Center of Fukuoka Gakuen.

\section{References}

1. Kimoto-Nira H, Suzuki C, Kobayashi M, Sasaki K, Kurisaki J, Mizumachi K. Anti-ageing effect of a lactococcal strain: analysis using senescence-accelerated mice. Br J Nutr 2007;98:117886.

2. Kimoto-Nira H, Nagakura Y, Kodama C, Shimizu T, Okuta M, Sasaki K, Koikawa N, Sakuraba K, Suzuki C, Suzuki Y. Effects of ingesting milk fermented by Lactococcus lactis H61 on skin health in young women: a randomized double-blind study. J Dairy Sci 2014;97:5898-903.

3. Sugimura T, Jounai K, Ohshio K, Suzuki H, Kirisako T, Sugihara Y, Fujiwara D. Long-term administration of pDC-Stimulative Lactococcus lactis strain decelerates senescence and prolongs the lifespan of mice. Int Immunopharmacol 2018;58:16672.

4. Pan D, Mei X. Antioxidant activity of an exopolysaccharide purified from Lactococcus lactis subsp. lactis 12. Carbohydr Polym 2010;80:908-14.

5. Holo H, Nilssen O, Nes IF. Lactococcin A, a new bacteriocin from Lactococcus lactis subsp. cremoris: isolation and characterization of the protein and its gene. J Bacteriol 1991;173:387987.

6. Bromberg R, Moreno I, Delboni RR, Cintra HC, Oliveira PTV. Characteristics of the bacteriocin produced by Lactococcus lactis subsp. cremoris CTC 204 and the effect of this compound on the mesophilic bacteria associated with raw beef. World J Microbiol Biotechnol 2005;21:351-8.

7. Zendo T, Koga S, Shigeri Y, Nakayama J, Sonomoto K. Lactococcin Q, a novel two-peptide bacteriocin produced by Lacto- coccus lactis QU 4. Appl Environ Microbiol 2006;72:3383-9.

8. Kitagawa N, Otani T, Inai T. Nisin, a food preservative produced by Lactococcus lactis, affects the localization pattern of intermediate filament protein in $\mathrm{HaCaT}$ cells. Anat Sci Int 2019;94:163-71.

9. Breukink E, de Kruijff B. The lantibiotic nisin, a special case or not? Biochim Biophys Acta 1999;1462:223-34.

10. Gupta SM, Aranha CC, Bellare JR, Reddy KV. Interaction of contraceptive antimicrobial peptide nisin with target cell membranes: implications for use as vaginal microbicide. Contraception 2009;80:299-307.

11. Mouritzen MV, Andrea A, Qvist K, Poulsen SS, Jenssen H. Immunomodulatory potential of Nisin A with application in wound healing. Wound Repair Regen 2019;27:650-60.

12. Ross MH, Pawlina W. Histology: a text and atlas. 7 th ed. Philadelphia: Wolters Kluwer/Lippincott Williams \& Wilkins Health; 2015.

13. Boukamp P, Petrussevska RT, Breitkreutz D, Hornung J, Markham A, Fusenig NE. Normal keratinization in a spontaneously immortalized aneuploid human keratinocyte cell line. J Cell Biol 1988;106:761-71.

14. Bikle DD, Xie Z, Tu CL. Calcium regulation of keratinocyte differentiation. Expert Rev Endocrinol Metab 2012;7:461-72.

15. Oda Y, Tu CL, Pillai S, Bikle DD. The calcium sensing receptor and its alternatively spliced form in keratinocyte differentiation. J Biol Chem 1998;273:23344-52.

16. Törmä H. Regulation of keratin expression by retinoids. Dermatoendocrinol 2011;3:136-40.

17. Tan KK, Salgado G, Connolly JE, Chan JK, Lane EB. Characterization of fetal keratinocytes, showing enhanced stem celllike properties: a potential source of cells for skin reconstruction. Stem Cell Reports 2014;3:324-38.

18. Kitagawa N, Inai Y, Higuchi Y, Iida H, Inai T. Inhibition of JNK in HaCaT cells induced tight junction formation with decreased expression of cytokeratin 5, cytokeratin 17 and desmoglein 3. Histochem Cell Biol 2014;142:389-99.

19. Kölsch A, Windoffer R, Leube RE. Actin-dependent dynamics of keratin filament precursors. Cell Motil Cytoskeleton 2009; 66:976-85.

20. Windoffer R, Borchert-Stuhlträger M, Leube RE. Desmosomes: interconnected calcium-dependent structures of remarkable stability with significant integral membrane protein turnover. J Cell Sci 2002;115(Pt 8):1717-32.

21. He Z, Fan J, Kang L, Lu J, Xue Y, Xu P, Xu T, Chen L. Ca2+ triggers a novel clathrin-independent but actin-dependent fast endocytosis in pancreatic beta cells. Traffic 2008;9:910-23.

22. De La Cruz N, Knebel-Mörsdorf D. Endocytic internalization of herpes simplex virus 1 in human keratinocytes at low temperature. J Virol 2021;95:e02195-20.

23. Wu XS, McNeil BD, Xu J, Fan J, Xue L, Melicoff E, Adachi R, Bai L, Wu LG. Ca(2+) and calmodulin initiate all forms of endocytosis during depolarization at a nerve terminal. Nat Neurosci 2009;12:1003-10.

24. Margiotta A, Bucci C. Role of intermediate filaments in vesicu- 
lar traffic. Cells 2016;5:20.

25. Mercer J, Helenius A. Virus entry by macropinocytosis. Nat Cell Biol 2009;11:510-20.

26. Lim JP, Gleeson PA. Macropinocytosis: an endocytic pathway for internalising large gulps. Immunol Cell Biol 2011;89:83643.

27. Kanlaya R, Sintiprungrat K, Chaiyarit S, Thongboonkerd V. Macropinocytosis is the major mechanism for endocytosis of calcium oxalate crystals into renal tubular cells. Cell Biochem Biophys 2013;67:1171-9.

28. King JS, Kay RR. The origins and evolution of macropinocytosis. Philos Trans R Soc Lond B Biol Sci 2019;374:20180158.

29. Veltman DM. Drink or drive: competition between macropinocytosis and cell migration. Biochem Soc Trans 2015;43:12932 .

30. Imura Y, Choda N, Matsuzaki K. Magainin 2 in action: distinct modes of membrane permeabilization in living bacterial and mammalian cells. Biophys J 2008;95:5757-65.

31. Henriques ST, Melo MN, Castanho MA. Cell-penetrating peptides and antimicrobial peptides: how different are they? Biochem J 2006;399:1-7.

32. Kordel M, Sahl HG. Susceptibility of bacterial, eukaryotic and artificial membranes to the disruptive action of the cationic peptides Pep 5 and nisin. FEMS Microbiol Lett 1986;34:139-44.

33. Nakase I, Niwa M, Takeuchi T, Sonomura K, Kawabata N, Koike Y, Takehashi M, Tanaka S, Ueda K, Simpson JC, Jones AT, Sugiura Y, Futaki S. Cellular uptake of arginine-rich peptides: roles for macropinocytosis and actin rearrangement. Mol Ther 2004;10:1011-22.

34. Takeuchi T, Futaki S. Current understanding of direct translocation of arginine-rich cell-penetrating peptides and its internalization mechanisms. Chem Pharm Bull (Tokyo) 2016;64:1431-7.

35. Poon GM, Gariépy J. Cell-surface proteoglycans as molecular portals for cationic peptide and polymer entry into cells. Biochem Soc Trans 2007;35(Pt 4):788-93.

36. Nakase I, Tadokoro A, Kawabata N, Takeuchi T, Katoh H, Hiramoto K, Negishi M, Nomizu M, Sugiura Y, Futaki S. Interaction of arginine-rich peptides with membrane-associated proteoglycans is crucial for induction of actin organization and macropinocytosis. Biochemistry 2007;46:492-501.

37. Nakase I, Osaki K, Tanaka G, Utani A, Futaki S. Molecular interplays involved in the cellular uptake of octaarginine on cell surfaces and the importance of syndecan- 4 cytoplasmic $\mathrm{V}$ domain for the activation of protein kinase $\mathrm{C} \alpha$. Biochem Biophys Res Commun 2014;446:857-62.

38. Schmidt N, Mishra A, Lai GH, Wong GC. Arginine-rich cellpenetrating peptides. FEBS Lett 2010;584:1806-13.

39. Palm-Apergi C, Lorents A, Padari K, Pooga M, Hällbrink M. The membrane repair response masks membrane disturbances caused by cell-penetrating peptide uptake. FASEB J 2009;23: 214-23.

40. Barnes L, Ino F, Jaunin F, Saurat JH, Kaya G. Inhibition of putative hyalurosome platform in keratinocytes as a mechanism for corticosteroid-induced epidermal atrophy. J Invest Dermatol 2013;133:1017-26.

41. Zemljič Jokhadar Š, Stojković B, Vidak M, Sorčan T, Liovic M, Gouveia M, Travasso RDM, Derganc J. Cortical stiffness of keratinocytes measured by lateral indentation with optical tweezers. PLoS One 2020;15:e0231606.

42. Lichti U, Anders J, Yuspa SH. Isolation and short-term culture of primary keratinocytes, hair follicle populations and dermal cells from newborn mice and keratinocytes from adult mice for in vitro analysis and for grafting to immunodeficient mice. Nat Protoc 2008;3:799-810.

43. Yang YW, Zhang CN, Cao YJ, Qu YX, Li TY, Yang TG, Geng D, Sun YK. Bidirectional regulation of i-type lysozyme on cutaneous wound healing. Biomed Pharmacother 2020;131:110700.

44. Otani T, Matsuda M, Mizokami A, Kitagawa N, Takeuchi H, Jimi E, Inai T, Hirata M. Osteocalcin triggers Fas/FasL-mediated necroptosis in adipocytes via activation of p300. Cell Death Dis 2018;9:1194.

45. Abé T, Kitagawa N, Yoshimoto S, Maruyama S, Yamazaki M, Inai T, Hashimoto S, Saku T. Keratin 17-positive Civatte bodies in oral lichen planus-distribution variety, diagnostic significance and histopathogenesis. Sci Rep 2020;10:14586.

46. Kabayama H, Takeuchi M, Taniguchi M, Tokushige N, Kozaki S, Mizutani A, Nakamura T, Mikoshiba K. Syntaxin 1B suppresses macropinocytosis and semaphorin 3A-induced growth cone collapse. J Neurosci 2011;31:7357-64.

47. Styers ML, Salazar G, Love R, Peden AA, Kowalczyk AP, Faun$\operatorname{dez} \mathrm{V}$. The endo-lysosomal sorting machinery interacts with the intermediate filament cytoskeleton. Mol Biol Cell 2004;15: 5369-82.

48. Bryant DM, Kerr MC, Hammond LA, Joseph SR, Mostov KE, Teasdale RD, Stow JL. EGF induces macropinocytosis and SNX1-modulated recycling of E-cadherin. J Cell Sci 2007; 120(Pt 10):1818-28.

49. Le TL, Yap AS, Stow JL. Recycling of E-cadherin: a potential mechanism for regulating cadherin dynamics. J Cell Biol 1999; 146:219-32.

50. Bratton DL, Fadok VA, Richter DA, Kailey JM, Guthrie LA, Henson PM. Appearance of phosphatidylserine on apoptotic cells requires calcium-mediated nonspecific flip-flop and is enhanced by loss of the aminophospholipid translocase. J Biol Chem 1997;272:26159-65.

51. Zhu J, Lin F, Brown DA, Clark RAF. A fibronectin peptide redirects $\mathrm{PDGF}-\mathrm{BB} / \mathrm{PDGFR}$ complexes to macropinocytosislike internalization and augments PDGF-BB survival signals. J Invest Dermatol 2014;134:921-9. 